\title{
EFFICACY OF FIRST AVAILABLE DIRECT-ACTING ANTIVIRAL AGENT IN TREATMENT OF CHRONIC HEPATITIS C; RESULTS FROM A SINGLE CENTRE IN PAKISTAN
}

\author{
Arif Qayyum Khan, Hala Mansoor, Javed Iqbal, Raja Yasser Shahbaz, Samina Fida, Muhammad Siddique \\ Combined Military Hospital Lahore/CMH Lahore Medical College and IOD/National University of Medical Sciences (NUMS) Pakistan
}

\begin{abstract}
Objective: To determine the efficacy of dual (sofosbuvir and ribavirin) and triple therapy (sofosbuvir-ribavirinpegylated interferon) for treatment of hepatitis $C$.

Study Design: Comparative cross sectional study.

Place and Duration of Study: Department of Medicine, Combined Military Hospital, Lahore, from Nov 2014 to Mar 2017.

Methodology: A total of 182 consecutive patients with age $\geq 18$ years and positive HCV RNA by polymerase chain reaction were included, while patients with haemoglobin of $<10 \mathrm{~g} / \mathrm{dl}$, albumin $<2 \mathrm{~g} / \mathrm{dl}$, platelet count of $<100 / \mathrm{uL}$, creatinine clearance of $<60 \mathrm{~mL} / \mathrm{min}$ or liver disease caused by non-hepatitis $\mathrm{C}$ related causes were excluded from study.

Results: Total 129 (70.8\%) were treated with dual and 53 (29.1\%) with triple therapy. Amongst patients with genotype 3 (158/182), the overall sustained virological response at 12 weeks (SVR 12) was $94.4 \%$ in patients with dual therapy while it was $97.3 \%$ with triple therapy. In non-cirrhotic patients it was $95 \%$ in treatment naïve and $100 \%$ in treatment experienced group. While in cirrhotic patients with genotype 3, SVR 12 with dual therapy was $83.3 \%(p=0.331)$ and $88.9 \%$ in treatment naïve and treatment experienced patients respectively, while it was $100 \%$ in both groups with triple therapy. SVR 12 for genotype $1(21 / 182)$ was $100 \%$, both for dual as well as for triple therapy. Haematological side effects dominated the clinical picture with $11.5 \%$ suffering from anaemia.

Conclusion: Both dual and triple therapy were effective in patients with hepatitis $C$ with acceptable level of side effects, genotype 3 being the most predominant genotype.
\end{abstract}

Keywords: Hepatitis C virus (HCV), SVR 12.

This is an Open Access article distributed under the terms of the Creative Commons Attribution License (http://creativecommons.org/licenses/by/4.0), which permits unrestricted use, distribution, and reproduction in any medium, provided the original work is properly cited.

\section{INTRODUCTION}

The global burden of hepatitis is enormous, with approximately 328 million people worldwide suffering either from hepatitis B or $\mathrm{C}^{1}$. In 2013, The Global Burden of Disease Study revealed that hepatitis accounted for about 1.45 million deaths worldwide, which was a major increase from 0.89 million in 1990. The morbidity, as measured in disability adjusted life years, also saw an upsurge to 0.87 million from 0.65 million ${ }^{1}$. The highest increase was for hepatitis $C$, for which Disability adjusted life years (DALYs) raised by $43 \%$. Worldwide, South and East Asia had 52\% mortality related to hepatitis, which was the greatest number of hepatitis related deaths in

Correspondence: Dr Arif Qayyum Khan, Combined Military Hospital, Lahore Pakistan

Received: 06 Nov 2019; revised received: 08 Feb 2020; accepted: 13 Feb 2020 absolute numbers ${ }^{2}$. In global hepatitis report, 2017 by World Health Organization, it was estimated that out of the hepatitis related deaths in 2015, 720000 were due to complications of decompensated chronic liver disease while 470,000 were related to hepatocellular carcinoma ${ }^{1}$. In 2017, a meta-analysis revealed that the estimated prevalence of hepatitis $\mathrm{C}$, in the average population of Pakistan was $8.4 \%$, with about $11.55 \%$ of the adults suffering from chronic hepatitis $C$ of which genotype 3 a was the most common type, affecting $63.45 \%{ }^{3}$. In 2016, the Global Health Sector Strategy, by World Health Assembly aimed to eliminate viral hepatitis as a threat to public health by $2030^{1}$. The treatment for hepatitis $C$ has witnessed a major change with the advent of newer direct acting antiviral agents. These medications are not only easy to administer with 
low pill burden, higher genetic barrier to resistance and fewer drug interactions but also have fewer side effects, so better tolerability and compliance. The ultimate end result is off course better viremic control in the long term ${ }^{4}$. While newer medications for hepatitis $C$ treatments are emerging at a rapid pace, it's not always possible, especially in the resource poor countries to get access to these newer treatment regimens for various reasons, most important of which remains the financial constraints. Considering the enormous burden to the health care set up posed by the hepatitis, physicians are at times forced to give older medications, till the time newer regimens are freely available at affordable prices in the local market. Hereby, we report our experience of treatment of chronic hepatitis C, comprising predominantly of genotype 3 , with both dual as well as triple therapy.

\section{METHODOLOGY}

This comparative cross sectional study was done from November 2014 to March 2017 at Combined Miliatary Hospital Lahore. A total of 182 patients, with chronic hepatitis $C$ with genotype; 1,3 and 4 , were selected using non-probability consecutive sampling technique and were analyzed to determine treatment outcomes. The study was conducted in accordance with the principles of Helsinki's declaration and good clinical practice guidelines and was approved by institution's ethics committee (reference No. 247/ERC/CMHLMC). Inclusion criteria included, evidence of hepatitis $C$ infection, as assessed by positive anti HCV antibodies by ELISA and positive HCV RNA by polymerase chain reaction (PCR) and age $\geq 18$ years while patients with haemoglobin of $<10 \mathrm{~g} / \mathrm{dl}$, albumin $<2 \mathrm{~g} / \mathrm{dl}$, platelet count of $<100 / \mathrm{uL}$, creatinine clearance of $<60$ $\mathrm{mL} / \mathrm{min}$ or liver disease caused by non-hepatitis $C$ related causes were excluded from study.

The diagnostic criteria of cirrhosis included consistent clinical, haematological (raised international normalized ratio and reduced platelet count), biochemical (raised bilirubin, low albumin and AST >ALT), radiological parameters (heterogenous liver parenchyma with irregular margins, nodular liver or enlarged left hepatic lobe on ultrasound, fibroscan reading of $12.5 \mathrm{kPa}$ or above, with or without other markers of portal hypertension like ascites, dilated portal veins, collaterals or splenomegaly) or an AST to platelet ratio index (APRI) of 2 or above.

During the study period interferon based triple regimen fell within the recommended AASLD and EASL guidelines, 2014. The decision whether to choose pegylated interferon based treatment regimen or not was based upon viral genotype, interferon eligibility, previous side effects, financial constraints and patient's willingness to receive injections. At the time of study, the cost of interferon based therapy was almost half to that of dual therapy because of short treatment duration and availability of pegylated interferon at reduced price. Out of 158 patients with genotype 3, 121 were treated with NS5B polymerase inhibitor sofosbuvir and ribavirin combination (dual therapy) while 37 with sofosbuvir, ribavirin and pegylated interferon combination (triple therapy). Of the 21 patients with genotype $1 ; 6$ were treated with dual while 15 with triple therapy. The two patients with genotype 4 were treated with dual while one was given triple therapy and so was the patient with mixed genotype 3 and 4 infection. Peg-INF a2a was administered 180ug per week subcutaneously, sofosbuvir 400 mg once daily while the ribavirin dose was adjusted according to the body weight. (1000 mg per day in those with body weight less than $75 \mathrm{~kg}$ and $1200 \mathrm{mg}$ for those with $>75 \mathrm{~kg}$. The standard duration of dual therapy was 24 weeks and that of triple therapy was 12 weeks.

\section{Statistical Analysis}

Rapid virological response (RVR) was defined as undetectable HCV RNA by PCR at week 4 of treatment ${ }^{5}$. Early virological response (EVR) as an undetectable or $\geq 2 \log$ reduction of serum HCV RNA at 12 weeks of treatment, while end of treatment response (ETR) was defined as an undetectable HCV RNA by PCR at the end of the therapy and sustained virological response (SVR) 
as an undetectable HCV RNA at 12 weeks after the end of therapy ${ }^{5}$. Non responder was defined as a person, who failed to have an undetectable HCV RNA at the end of the therapy ${ }^{5}$. SVR was determined using the Pearson method by using statistical package of social sciences (SPSS) ver-

\section{RESULTS}

Out of 182 patients, majority were females $99(54.5 \%)$, mean age of study population was 44.9, standard deviation (SD) 11.96 and range was $18-73$ years. Out of 182, there were 38 (20.8\%) patients with cirrhosis; majority of whom 35

Table-I: Demographic characteristics of the sample ( $\mathrm{N}=182)$.

\begin{tabular}{l|c|c|c}
\hline Parameters & Total patients (182) & Genotype 1 (21) & Genotype 3 (158) \\
\hline Mean age (years) & 44.9 & 42.76 & 45.16 \\
SD & 11.96 & 10.78 & 12.18 \\
\hline Female gender-no. (\%) & $99(54.5)$ & $13(61.9)$ & $85(53.8)$ \\
\hline HCV subtypes-no(\%) & 182 & $21(11.5)$ & $158(86.8)$ \\
\hline Mean bilirubin (mg/dl) & 0.82 & 0.64 & 0.84 \\
SD & 0.68 & 0.27 & 0.72 \\
\hline Mean AST IU/ml (range) & $64.5(15-233)$ & $52.76(27-134)$ & $66.27(15-233)$ \\
SD & 40.39 & 40.38 & 41.73 \\
\hline Mean ALT IU/ml (range) & $68.56(10-625)$ & $54.71(18-116)$ & $70.72(10-625)$ \\
SD & 56.78 & 56.77 & 59.73 \\
\hline TN; cirrhotic-no (\%) & $24(13)$ & $2(8.33)$ & $22(13.9)$ \\
\hline TN; non-cirrhotic -no (\%) & $97(53.3)$ & $13(13.4)$ & $82(51.9)$ \\
\hline TE; cirrhotic-no (\%) & $14(7.7)$ & - & $14(8.86)$ \\
\hline TE; non-cirrhotic-no (\%) & $47(25.8)$ & $6(12.76)$ & $40(25.3)$ \\
\hline Table-II: Response rate with & & \\
\hline
\end{tabular}

Table-II: Response rate with dual therapy among patients.

\begin{tabular}{|c|c|c|c|c|c|c|}
\hline \multirow{2}{*}{ Parameters } & \multirow{2}{*}{$\begin{array}{c}\text { Total Number } \\
\text { of Patients }\end{array}$} & \multicolumn{5}{|c|}{ Dual Therapy } \\
\hline & & No. of Patients & ETR & NR & SVR 12 & LTF \\
\hline Overall & 182 & 129 & $109(96.5 \%)$ & $4(3.5 \%)$ & $107(94.7 \%)$ & 16 \\
\hline Genotype 1 & 21 & 6 & $3(100 \%)$ & - & $3(100 \%)$ & 3 \\
\hline $\mathrm{TN}$, cirrhotic & 2 & 1 & $1(100 \%)$ & - & $1(100 \%)$ & - \\
\hline TN, non-cirrhotic & 13 & 3 & $1(100 \%)$ & - & $1(100 \%)$ & 2 \\
\hline TE, cirrhotic & - & - & - & - & - & - \\
\hline TE, non-cirrhotic & 6 & 2 & $1(100 \%)$ & - & $1(100 \%)$ & 1 \\
\hline Genotype 3 & 158 & 121 & $104(96.2 \%)$ & $4(3.7 \%)$ & $102(94.4 \%)$ & 13 \\
\hline $\mathrm{TN}$, cirrhotic & $22^{*}$ & 16 & $10(83.3 \%)$ & $2(16.66 \%)$ & $10(83.3 \%)$ & 4 \\
\hline TN, non-cirrhotic & 82 & 63 & $58(96.6 \%)$ & $2(3.33 \%)$ & $57(95 \%)$ & 3 \\
\hline TE, cirrhotic & 14 & 12 & $9(100 \%)$ & $1(11.1 \%)$ & $8(88.9 \%)$ & 3 \\
\hline TE, non cirrhotic & 40 & 30 & $27(100 \%)$ & - & $27(100 \%)$ & 3 \\
\hline Genotype 4 & 3 & 2 & $2(100 \%)$ & - & $2(100 \%)$ & - \\
\hline $\mathrm{TN}$, cirrhotic & - & - & - & - & - & - \\
\hline TN, non-cirrhotic & 2 & 1 & $1(100 \%)$ & - & $1(100 \%)$ & - \\
\hline TE, cirrhotic & - & - & - & - & - & - \\
\hline TE, non-cirrhotic & 1 & 1 & $1(100 \%)$ & - & $1(100 \%)$ & - \\
\hline
\end{tabular}

TN: treatment naïve; TE: treatment experienced; NR: non-responder; LTF:lost to follow up, ETR: end of treatment response; SVR: sustained virologic response, *One TN, cirrhotic was treated with Peg IF and ribavirin

sion 25 of the windows. Descriptive statistics of quantitative variables were expressed as mean and standard deviation while those of qualitative variables as frequency and percentages.
(19.2\%) had compensated and there were only 3 $(1.65 \%)$ patients with decompensated cirrhosis. In addition there were also $3(1.65 \%)$ patients with living donor liver transplant. 
Genotype 3 was the predominant type of viral infection, accordant with the prevalence of hepatitis $C$ in this region, affecting 158 (86.8\%) of the patients, while 21 patients (10.95\%) had genotype 1 and there were 3 patients with genotype 4 (1.6\%). One patient had dual infection with HCV genotype 3 and 4 table-I.

One hundred and twenty one (66.5\%) patients were treatment naïve, while 61 (33.5\%) combination, $9(4.9 \%)$ had been treated twice; first with standard interferon and ribavirin and later with pegylated interferon and ribavirin; while one was intolerant to inter-feron, so had incomplete prior treatment.

Of the 53 patients in the triple therapy group, all but one patient achieved ETR while 2 were lost to follow up. Of 129 patients in the dual therapy group, $109(96.5 \%)$ patients achieved

Table-III: Response rate with triple therapy among patients.

\begin{tabular}{|c|c|c|c|c|c|c|}
\hline \multirow{2}{*}{ Parameters } & \multirow{2}{*}{$\begin{array}{c}\text { Total Number } \\
\text { of Patients }\end{array}$} & \multicolumn{5}{|c|}{ Triple Therapy } \\
\hline & & No. of Patients & ETR & NR & SVR 12 & LTF \\
\hline Overall & 182 & 53 & $50(98 \%)$ & $1(2 \%)$ & $50(98 \%)$ & 2 \\
\hline Genotype 1 & 21 & 15 & $13(100 \%)$ & - & $13(100 \%)$ & 2 \\
\hline TN, cirrhotic & 2 & 1 & 1 & - & 1 & - \\
\hline TN, non-cirrhotic & 13 & 10 & $8(100 \%)$ & - & $8(100 \%)$ & 2 \\
\hline TE, cirrhotic & - & - & - & - & - & - \\
\hline TE, non cirrhotic & 6 & 4 & $4(100 \%)$ & - & $4(100 \%)$ & - \\
\hline Genotype 3 & 158 & 37 & $36(97.3 \%)$ & $1(2.8 \%)$ & $36(97.3 \%)$ & - \\
\hline TN, cirrhotic & $22^{*}$ & 5 & $5(100 \%)$ & - & $5(100 \%)$ & - \\
\hline TN, non-cirrhotic & 82 & 20 & $19(95 \%)$ & $1(5 \%)$ & $19(95 \%)$ & - \\
\hline TE, cirrhotic & 14 & 2 & $2(100 \%)$ & - & $2(100 \%)$ & - \\
\hline TE, non cirrhotic & 40 & 10 & $10(100 \%)$ & - & $10(100 \%)$ & - \\
\hline Genotype 4 & 3 & $1(100 \%)$ & $1(100 \%)$ & - & $1(100 \%)$ & - \\
\hline $\mathrm{TN}$, cirrhotic & - & - & - & - & - & - \\
\hline TN, non-cirrhotic & 2 & $1(100 \%)$ & $1(100 \%)$ & - & $1(100 \%)$ & - \\
\hline TE, cirrhotic & - & - & - & - & - & - \\
\hline TE, non-cirrhotic & 1 & - & - & - & - & - \\
\hline
\end{tabular}

TN: treatment naïve; TE: treatment experienced; NR: non-responder; LTF:lost to follow up, ETR: end of treatment response; SVR: sustained virological response, ${ }^{*}$ One TN, cirrhotic was treated with Peg IF and ribavirin

Table-IV: Correlation of SVR 12 and other factors among patients.

\begin{tabular}{l|c|c|c|c|c|c}
\hline Factors & \multicolumn{3}{|c|}{ Univariate } & \multicolumn{3}{c}{ Multivariate } \\
\hline & $\begin{array}{c}\text { Adjusted } \\
\text { Odds ratio }\end{array}$ & $\boldsymbol{p}$-value & $\mathbf{9 5 \% \mathbf { C I }}$ & $\begin{array}{c}\text { Adjusted } \\
\text { Odds ratio }\end{array}$ & $\boldsymbol{p}$-value & $\mathbf{9 5 \%} \mathbf{C I}$ \\
\hline Age & 0.93 & 0.614 & $0.45-1.93$ & 1.02 & 0.53 & $0.84-1.11$ \\
\hline Gender & 0.73 & 0.315 & $0.63-1.8$ & 0.29 & 0.28 & $0.03-2.8$ \\
\hline Baseline Viral load & 1.38 & 0.54 & $0.40-4.73$ & 1 & 0.18 & $1-1$ \\
\hline ALT baseline & 0.28 & 0.826 & $0.5-3.5$ & 0.96 & 0.14 & $0.92-1.01$ \\
\hline AST baseline & 0.37 & 0.545 & $0.6-4.2$ & 0.98 & 0.15 & $1-1$ \\
\hline
\end{tabular}

${ }^{*}$ CI: Confidence Interval

were treatment experienced. Out of these $61 ; 29$ $(15.9 \%)$ were relapsers and $32(17.6 \%)$ were nonresponder to either treatment with combination of standard or pegylated interferon (Peg-IFN) with ribavirin. Eighteen (9.9\%) were previously treated with standard interferon and ribavirin, 33 $(18.1 \%)$ with pegylated interferon and ribavirin
ETR, 4 (3.5\%) were non responders while 16 patients were lost to follow up during treatment, at variable intervals of time. All four non-responders, were treatment naïve females, with genotype 3 infection. Two of them had cirrhosis. There were no significant co-morbidities apart from ischemic heart disease in one patient. Of the 109 
patients with ETR, 107 (94.7\%) were successful in achieving SVR, whereas 2 patients relapsed at 12 weeks post-treatment. One of them was an overweight, cirrhotic male patient, with genotype 3 , who was treated twice before, initially with standard interferon and ribavirin and later on with pegylated interferon and ribavirin. The reason for treatment with dual therapy was refusal of triple therapy. He did not achieve RVR, however his PCR on 8th week of treatment was negative and he achieved ETR, however could not attain SVR 12. The other was a 45 years old lady with genotype 3; who was treatment naïve with no co-morbidities, who had an early virological response and whose PCR was negative twice during treatment as well as at the end of treatment. She, however relapsed 12 weeks, post- treatment. She had a fatty liver on abdominal ultrasound.

Amongst patients with genotype 3, the overall SVR 12 was $94.4 \%$ in patients with dual therapy while it was $97.3 \%$ with triple therapy. Subgroup analysis further showed that amongst cirrhotic patients with genotype 3, the SVR 12 with dual therapy was $83.3 \%$ and $88.9 \%$ in treatment naïve and treatment experienced patients respectively, while it was better with triple therapy, being $100 \%$ in both groups, however it did not reach the statistical significance, owing probably to the small sample size in both groups; $(p=0.331$ and 0.62 respectively). In non-cirrhotic patients it was similar with both treatment regimens, being $95 \%$ in treatment naïve and $100 \%$ in treatment experienced group. SVR 12 for genotype 1 was $100 \%$, both for dual as well as for triple therapy. However, the sample size of patients with genotype 1, whose SVR 12 could be ascertained was considerably small $(16 / 21)$, as 5 were lost to follow up (table-I,II).

The main haematological side effect of treatment was anaemia, which required use of erythropoietin in $21(11.5 \%)$ patients, $4(7.7 \%)$ in the triple therapy and $17(13.2 \%)$ in the dual therapy group. Five $(23.8 \%)$ out of these 21 patients were cirrhotic and 16 (76.2\%) were female. One of these patients also required concomitant use of granulocytecolony stimulating factor, due to signifi- cant neutropenia of 0.8 at $8 / 12$ week of triple therapy. This was a cirrhotic lady, with genotype 3 , who was a relapser after treatment with standard interferon and ribavirin. She was able to complete treatment and was successful in gaining long term viral suppression i.e her PCR remained negative 60 weeks post-treatment.

Univariate as well as multivariate logistic regression analysis revealed no significant correlation between SVR 12 and other variables, including age, gender, level of liver enzymes or viral load of the patient table-IV.

\section{DISCUSSION}

Over the years, treatment of hepatitis $C$ has witnessed major changes, with newer medications emerging at a rapid pace. Genotype 3 is predominant genotype in South and Central Asia, representing the $71.6 \%$ of the global prevalence ${ }^{6,7}$. It also carries the unique property of increased incidence of steatosis and swift fibrosis, thus increasing the risk for hepatocellular carcinoma ${ }^{8-12}$. In this era of direct acting anti-viral drugs (DAA), genotype 3 has been considered the most difficult genotype to treat ${ }^{13}$. In 2013, Sofosbuvir, an NS5B polymerase inhibitor made the major breakthrough for treatment of genotype 3 infection, and since its approval has remained the backbone for the treatment of hepatitis $C^{14}$. Sofosbuvir gained approval for use in local market in Pakistan in November 2014. The high initial cost and lack of availability in government sector hospitals, was the primary reason for its limited initial prescription. It was not until, October 2015, in a country which is considered to carry the second highest global burden of infection with approximately 8 million people infected with hepatitis C, 14 pharmaceutical companies were allowed to manufacture it locally, leading to a fall in price and easy availability to many.

The patients during our study period were treated with dual or triple therapy according to the recommended AASLD or EASL guidelines at the time of study ${ }^{15-16}$. The four large clinical trials from the West that included the patients with genotype 3 to assess the efficacy of sofosbuvir 
and ribavirin combination included the Fission, Fusion, Positron and Valence. In Fission the SVR 12 was only $56 \%$ for SOF/RBV versus $63 \%$ for PEG/RBV and it further dropped to $47 \%$ in patients with cirrhosis $4,17,18,20$.

Two subsequent trials Positron and Fusion again elaborated the same fact regarding sofosbuvir based treatment. Positron confirmed that 12 weeks of therapy with SOF/RIB was not quintessential for genotype 3, with an SVR 12 of $68 \%(n=57 / 84)$ in patients without cirrhosis that further dropped to $21 \%(n=3 / 14)$ in those with cirrhosis, making this an unacceptable treatment option in cirrhotic patients ${ }^{18}$.

Considering the limitations of SOF/RBV treatment regimen in particularly difficult to treat genotype 3 patients, BOSON trial was designed, which included treatment experienced cirrhotic patients with genotype 2 and both treatment naïve as well as experienced patients with genotype 3. Three patients who were on 24 weeks of treatment with dual therapy had virological failure during treatment. The response rate were lower in both treatment naïve and treatment experienced cirrhotic, with being $82 \%(n=18 / 22)$ and $76 \%(n=26 / 34)$ with 24 weeks of SOF/RBV while it was $91 \%(21 / 23)$ and $86 \%(n=30 / 35)$ with SOF/ PEG/RBV respectively. IL 28B non CC allele and male sex were associated with relapse in both 16 and 24 weeks of SOF/RBV treatment regimens. Cirrhosis was associated with relapse in SOF/P $\mathrm{EG} / \mathrm{RBV}$ and 16 weeks of SOF/RBV treatment but not with 24 weeks of SOF/RBV. This study established that SOF/PEG/RBV was significantly superior as compared to other two treatment regimens, with all subgroups achieving SVR 12 $>90 \%$, with the exception of cirrhosis where SVR 12 was $86 \%$ although it still outmatched others. It was also established that dual therapy with SOF/ RBV remains an alternative acceptable treatment option for patients who are unwilling or cannot take interferons for various reasons ${ }^{19}$.

Lonestar-2 trial substantiated that triple therapy was the most effective treatment regimen for interferon eligible patients till that time with
SVR 12 of $83 \%$ in treatment experienced patients with genotype 3 , both with and without cirrho$\operatorname{sis}^{20}$. Considering the efficacy of triple therapy all our interferon eligible patients were given its choice. The response rate in our study was quite similar to the above mentioned trials, with an overall SVR 12 of $>83 \%$ in cirrhotic patients with genotype 3 with dual therapy, which was $83.3 \%$ in treatment naïve and $88.9 \%$ in treatment experienced cirrhotic. In comparison, there was $100 \%$ response rate (SVR12) with triple therapy, in both treatment naïve $(5 / 5)$ and treatment experienced (2/2) cirrhotic.

In treatment naïve patients with genotype 1 , 24 weeks of SOF/RBV was found to be ineffective, in single center phase 2, NIH Spare trial, which showed a poor SVR 24 of $68 \%$, which further dropped to $50 \%$ in those with advanced fibrosis ${ }^{21}$. Once again the efficacy of triple therapy for genotype 1, 4, 5 and 6 was shown by Neutrino study. The SVR 12 for genotype 1 was $89 \%$; $82 \%$ in patients with genotype $1 \mathrm{~b}$ and $92 \%$ for $1 \mathrm{a}$. There was splendid response across other genotypes, with $96 \%$ in genotype $4(n=27 / 28)$ and $100 \%$ in genotype 5 and 6 , though the sample size was quite small for genotype $5(n=1)$ and $6(n=6)$. Cirrhosis and non-CC IL28B genotype were associated with poor response $(80 \%$ with cirrhosis and $92 \%$ without cirrhosis $)^{4}$. Considering the superior response rate with triple therapy, $71.4 \%$ of our patients, with genotype 1 , who were interferon eligible, were treated with triple therapy. However both triple as well as dual therapy was equally effective in genotype 1, achieving an overall SVR 12 of $100 \%$. Both treatments were equally efficacious in both treatment naïve and treatment experienced patients, as well as in those with or without cirrhosis. However the small sample size of patients with genotype $1(21 / 182)$ remains an important limiting factor, reducing the power of the study to draw substantial conclusions for this type, which may also account for variance in treatment response across this genotype from the literature.

Both dual as well as triple therapy were well tolerated with low overall side effects, seen in 
$7.7 \%$ of patients with triple and $13.2 \%$ with dual therapy. However none of the patients experienced any intolerable side effects warranting the need for discontinuation of treatment.

\section{CONFLICT OF INTEREST}

This study has no conflict of interest to be declared by any author.

\section{REFERENCES}

1. Global hepatitis report. Geneva, World Health Organization, 2017 [Internet]. http://www.who.int/hepatitis

2. Stanaway, JD, Flaxman, AD, Naghavi, M, Fitzmaurice C, Theo V, Ibrahim A, et al. The global burden of hepatitis from 1990 to 2013: finding from the Global Burden of Disease Study. Lancet1 2016; 388(10049): 1081-88.

3. Arshad A, Ashfaq UA. Epidemiology of Hepatitis C Infection in Pakistan: current estimate and major risk factors. Crit Rev Eukaryot Gene Expr 2017; 27(1): 63-77.

4. Lawitz E, Mangia A, Wyles D, Rodriguez-Torres M, Hassanein $\mathrm{T}$, Gordon SC, et al. Sofosbuvir for previously untreated chronic hepatitis C infection. N Engl J Med 2013; 368(20): 1878-87.

5. Yu JW, Wang GQ, Sun LJ, Li XG, Li SC. Predictive value of rapid virological response and early virological response on sustained virological response in HCV patients treated with pegylated interferon alpha-2a and ribavirin. J Gastroenterol Hepatol 2007; 22(6): 832-36.

6. Chan A, Patel K, Naggie S. Genotype 3 infection: The last stand of hepatitis C virus. Drugs 2017; 77(2): 131-44.

7. Gower E, Estes C, Blach S, Razavi-Shearer K, Razavi H. Global epidemiology and genotype distribution of the hepatitis $C$ virus infection. J Hepatol 2014; 61(1 Suppl): S45-57.

8. Bochud PY, Cai T, Overbeck K, Bochud M, Dufour JF, Mullhaupt B, et al. Genotype 3 is associated with accelerated fibrosis progression in chronic hepatitis C. J Hepatol 2009; 51(4): 655-66.

9. Hwang SJ. Hepatic steatosis and hepatitis C: Still un-happy bedfellows?. J Gastroenterol Hepatol 2011; 26(Suppl 1): 96-01.

10. Roingeard P. Hepatitis $C$ virus diversity and hepatic steatosis. J Viral Hepatit 2013; 20(2): 77-84.
11. Patton HM, Patel K, Behling C, Bylund D, Blatt LM, Vallee M, et al. The impact of steatosis on disease progression and early and sustained treatment response in chronic hepatitis C patients. J Hepatol 2004; 40(3): 484-90.

12. Poynard T, Ratziu V, Charlotte F, Goodman Z, McHutchison J, Albrecht J. Rates and risk factors of liver fibrosis progression in patients with chronic hepatitis C. J Hepatol 2001; 34(5): 730-39.

13. Tapper EB, Afdhal NH. Is 3 the new 1:perspectives on virology, natural history and treatment for hepatitis $C$ genotype 3 . J Viral Hepatit 2013; 20(10): 669-77.

14. OECD. Health at a glance 2017. OECD indicators. Paris: Organization for Economic Co-operation and Development, November 10 2017. Available at http://www.oecd.org/health / health-at-aglance.html. Accessed Dec 20, 2017.

15. Hepatitis C guidance: AASLD-IDSA recommendations for testing, managing, and treating adults infected with hepatitis $\mathrm{C}$ virus. Hepatology 2015; 62(3): 932-54.

16. Foster GR, Afdhal N, Roberts SK, Bräu N, Gane EJ, Pianko S, et al. Sofosbuvir and velpatasvir for HCV genotype 2 and 3 infection. N Engl J Med 2015; 373(27): 2608-17.

17. Jacobson IM, Gordon SC, Kowdley KV, Yoshida EM, RodriguezTorres M, Sulkowski MS, et al. Sofosbuvir for hepatitis C genotype 2 or 3 in patients without treatment options. England J Med 2013; 368(20): 1867-77.

18. Zeuzem S, Dusheiko GM, Salupere R, Mangia A, Flisiak R, Hyland RH, et al. Sofosbuvir and ribavirin in HCV genotypes 2 and 3. New England J Med 2014; 370(21): 1993-01.

19. Foster GR, Pianko S, Brown A, Forton D, Nahass RG, George J, et al. Efficacy of sofosbuvir plus ribavirin with or without peginterferon-alfa in patients with hepatitis $C$ virus genotype 3 infection and treatment-experienced patients with cirrhosis and hepatitis C virus genotype 2 infection. Gastroenterol 2015; 149(6): 1462-70.

20. LawitzE, PoordadF, Brainard DM, Hyland RH, An D, DvorySobol $\mathrm{H}$, et al. Sofosbuvir with peginterferon-ribavarin for 12 weeks in previously treated patients with hepatitis $C$ genotype 2 or 3 and cirrhosis. Hepatol 2015; 61(3):769-75.

21. Osinusi A, Meissner EG, Lee YJ, Bon D, Heytens L, Nelson A, et al. Sofosbuvir and ribavirin for hepatitis $C$ genotype 1 in patients with unfavorable treatment characteristics: a randomized clinical trial. J Am Med Assoc 2013; 310(18): 804-11. 